\title{
PENDOKUMENTASIAN PERAWAT TERHADAP ASUHAN KEPERAWATAN DALAM PELAKSANAAN PELAYANAN PASIEN DI RUMAH SAKIT
}

Ade Sulistya Lubis/181101121

adesulistyalubis@gmail.com

\begin{abstract}
Abstrak
Latar belakang: Rumah sakit merupakan sebuah organisasi kesehatan yang sangat bermanfaat guna memberikan pelayanan kesehatan bagi masyarakat. Tujuan: agar dapat mengetahui bagaimana pendokumentasian perawat terhadap asuhan keperawatan dalam pelaksanaan pelayanan pasien di Rumah sakit. Metode: menggunakan metode tersearch dan analisis dari berbagai sumber seperti buku teks, buku referensi jurnal, e-book, dan juga membandingkan beberapa jurnal yang berhubungan dengan Pendokumentasian perawat terhadap asuhan keperawatan dalam pelaksanaan pelayanan pasien di Rumah sakit. Hasil: Salah satu pelayanan kesehatan yang diberikan oleh tenaga kesehatan adalah pelayanan keperawatan, Sebagai bagian dari pelayanan kesehatan, maka pelayanan keperawatan yang dilakukan oleh tenaga perawat memiliki tugas diantaranya memberikan asuhan keperawatan Kesimpulan: Dokumentasi keperawatan merupakan bentuk dokumen asuhan keperawatan sebagai salah satu alat pembuktian atas tindakan perawat selama menjalankan tugas pelayanan keperawatan. Dokumen asuhan keperawatan sangat diperlukan untuk kepentingan pasien maupun perawat, akan tetapi pada kenyataannya masih banyak dokumen asuhan keperawatan yang isinya belum sesuai baik dari segi kuantitas maupun kualitas.
\end{abstract}

Kata kunci: Pendokumentasian, Asuhan keperawatan, Rumah sakit

Background: The hospital is a health organization that is very useful in providing health services for the community. Objective: to be able to know how to document nurses on nursing care in the implementation of patient services in hospitals. Method: using the search method and analysis from various sources such as textbooks, journal reference books, e-books, and also comparing several journals related to Documenting nurses to nursing care in the implementation of patient services in hospitals. Results: One of the health services provided by health workers is nursing services. As part of health services, the nursing services performed by nurses have the task of providing nursing care Conclusion: Nursing documentation is a form of nursing care document as a proof of the actions of nurses during their nursing service duties. Nursing care documents are needed for the benefit of patients and nurses, but in reality there are still many nursing care documents whose contents are not appropriate both in terms of quantity and quality.

Keywords: Documentation, Nursing care, Hospital 
PENDAHULUAN

\section{LATAR BELAKANG}

Rumah sakit merupakan sebuah organisasi kesehatan yang sangat bermanfaat guna memberikan pelayanan kesehatan bagi masyarakat, sebagaimana tertera dalam UU RI No 44 pasal 1 (2009, p.2). Setiap tenaga kesehatan yang bekerja dirumah sakit harus bekerja sesuai dengan standar profesi, standar pelayanan rumah sakit, standar prosedur operasional yang berlaku, etika profesi, menghormati hak pasien, dan mengutamakan keselamatan pasien. Tenaga kesehatan tersebut diantaranya tenaga medis dan penunjang medis, tenaga keperawatan, tenaga kefarmasian, tenaga manajemen rumah sakit dan tenaga non kesehatan UU RI No 44 pasal 12-13 (2009, p.11-12).

Salah satu pelayanan kesehatan yang diberikan oleh tenaga kesehatan adalah pelayanan keperawatan, Sebagai bagian dari pelayanan kesehatan, maka pelayanan keperawatan yang dilakukan oleh tenaga perawat memiliki tugas diantaranya memberikan asuhan keperawatan (Hidayat, 2011, p.75).

Asuhan keperawatan adalah suatu pendekatan untuk pemecahan masalah yang memampukan perawat untuk mengatur dan memberikan asuhan keperawatan. Standar asuhan yang tercantum dalam Standar Praktik Klinis Keperawatan terdiri dari lima fase asuhan keperawatan: 1) Pengkajian; 2) Diagnosa; 3) Perencanaan; 4) Implementasi; dan 5) Evaluasi. Salah satu manfaat dari penerapan asuhan keperawatan yang baik adalah meningkatkan mutu dan kualitas pelayanan dalam bidang keperawatan (Kozier, 2010).

\section{TUJUAN}

Tujuan pembandigan dari beberapa jurnal dan sumber lainnya agar dapat mengetahui bagaimana pendokumentasian perawat terhadap asuhan keperawatan dalam pelaksanaan pelayanan pasien di Rumah sakit.

\section{METODE}

Jurnal ini menggunakan metode tersearch dan analisis dari berbagai sumber seperti buku teks, buku referensi jurnal, ebook, dan juga membandingkan beberapa jurnal yang berhubungan dengan Pendokumentasian perawat terhadap asuhan keperawatan dalam pelaksanaan pelayanan pasien di Rumah sakit. Dari analisi berbagai sumber digunakan Untuk 
mengetahui bagaimana Pendokumentasian perawat terhadap asuhan keperawatan dalam pelaksanaan pelayanan pasien di Rumah sakit. Penulisan jurnal ini dimulai pada tanggal 10 Desember 2019. Pengolahan jurnal dilakukan dengan metode membandingkan beberapa jurnal yang berhubungan dengan Pendokumentasian perawat terhadap asuhan keperawatan dalam pelaksanaan pelayanan pasien di Rumah sakit.

\section{HASIL}

Dari jurnal (Biki, P.A.U, (2015). Gambaran Kinerja Perawat dalam Memberikan Asuhan Keperawatan di Ruang Interna di RSUD PROF. DR.H.Aloei Saboe Kota Gorontalo. Universitas Negeri Gorontalo: Jurnal Keperawatan. ) hasil penelitian yang dilakukan oleh Sugiyati mengenai Hubungan Pengetahuan Perawat dalam Dokumentasi Keperawatan dengan Pelaksanaannya di Rawat Inap RSI Kendal tahun 2015, penelitian ini menjelaskan bahwa dokumentasi keperawatan yang dilakukan oleh perawat di Rumah Sakit Islam Kendal berada dalam kategori baik yaitu 24 orang $(80,0 \%)$ sedangkan yang tidak lengkap, yaitu terdiri dari pengkajian
$20 \%$, diagnosa $12,6 \%$, perencanaan $28 \%$, implementasi $3 \%$ dan evaluasi $8 \%$. Menurut Nursalam (2001), rencana keperawatan sebagai suatu dokumen tulisan tangan dalam menyelesaikan masalah, tujuan dan intervensi. Rencana keperawatan merupakan metode komunikasi tentang asuhan keperawatan kepada klien.

Penelitian ini tidak sejalan dengan hasil penelitian yang dilakukan Supratman dan Utami mengenai pendokumentasian asuhan keperawatan ditinjau dari beban kerja perawat tahun 2009. Penelitian ini menjelaskan bahwa pendokumentasian asuhan keperawatan pada tahap implementasi keperawatan termasuk kedalam kategori baik yaitu $27(84,4 \%)$ responden, sedangkan $5 \quad(15,6 \%)$ responden termasuk dalam kategori buruk. Dari jurnal (L.M. Harmain, Siswanto. 2013. Faktor-Faktor Yang Berhubungan Dengan Kelengkapan Pendokumentasian Asuhan Keperawatan: Jurnal Keperawatan Indonesia, Volume 16 No.2, Juli, hal 7784 pISSN 1410-4490, eISSN 2354-9203) hasil penelitian ini sejalan dengan penelitian Lusianah (2008) yang menyatakan bahwa ada hubungan antara 
kualitas dokumentasi asuhan keperawatan dengan pelatihan, kualitas dokumentasi akan meningkat sebesar 1,60 kali pada perawat yang pernah pelatihan dibanding yang belum pernah pelatihan. Hasil penelitian ini juga sejalan dengan pendapat Jefferies, Johnson, Nicholls, dan Lad (2012) fokus dari peningkatan pengetahuan melalui pelatihan meningkatkan dokumentasi keperawatan yang dilakukan oleh perawat. Pentingnya pelatihan pendokumentasian bagi perawat memberikan dampak positif terhadap kinerja perawat khususnya dalam melakukan pendokumentasian asuhan keperawatan. Dampak positif pelatihan yang sudah tergambar pada hasil penelitian ini harus menjadi bahan pertimbangan manajemen rumah sakit dalam melakukan pelatihan secara periodik untuk memberikan kesempatan bagi perawat yang belum mendapatkan pelatihan untuk lebih meningkatkan pendokumentasian.

\section{PEMBAHASAN}

Menurut Nurachmah (2001), salah satu wujud asuhan keperawatan yang bermutu ialah pelaksanaan pendokumentasian asuhan secara baik dan terus menerus.

Dari jurnal (L.M. Harmain, Siswanto. 2013. Faktor-Faktor Yang Berhubungan Dengan Kelengkapan Pendokumentasian

Asuhan

\section{Keperawatan: Jurnal Keperawatan}

Indonesia, Volume 16 No.2, Juli, hal 77 84 pISSN 1410-4490, eISSN 2354-9203). Pendokumentasian merupakan bukti legal pelaksanaan pelayanan di rumah sakit. Kualitas pelayanan disuatu rumah sakit salah satunya dapat dilihat dari pelaksanaan pendokumentasian asuhan keperawatan (Wang, Hailey, \& Yu, 2011).

Pendokumentasian asuhan keperawatan dilakukan sebagai bukti tindakan keperawatan sudah dilakukan secara professional dan legal sehingga dapat memberikan perlindungan pada perawat dan pasien (Iyer \& Camp, 2005). Pendokumentasian berguna bagi rumah sakit dalam meningkatkan standar akreditasi, sebagai alat komunikasi antar profesi, indikator pelayanan mutu, bukti tanggung jawab, dan tanggung gugat perawat, sumber data dan sebagai sarana penelitian (Teytelman, 2002; Jefferies, Johnson, Nicholls \& Lad, 2012). 
Dari jurnal (Supratman, Yuni

Wulan

Utami.2009.

Pendokumentasian

Asuhan

Keperawatan Ditinjau Dari Beban Kerja

Perawat: Berita Ilmu Keperawatan ISSN

1979-2697, Vol. 2 No. 1, Maret 2009: 7-

12) Menurut Marelli (1997), dokumentasi asuhan mencakup lima hal yaitu pengkajian data pasien, penegakkan diagnosa keperawatan, perencanaan tindakan, pelaksanaan tindakan dan penilaian hasil tindakan keperawatan.

Pendokumentasian menjadi kurang efektif disebabkan oleh beban kerja perawat yang bertambah yang disebabkan oleh banyaknya pekerjaan dan berulang karena disebabkan oleh perawat itu sendiri (Braaf, Manias, \& Riley, 2011). Sedangkan Sugiharto, Keliat, dan Hariyati (2012) menyatakan bahwa perawat dalam melakukan pekerjaannya kerap menyebabkan demotivasi yang disebabkan oleh beberapa hal seperti jam kerja yang panjang, dampak jam kerja malam, kekurangan tenaga keperawatan karena beban kerja tinggi, gaji rendah, dan kurang penghargaan.

\section{PENUTUPAN}

\section{KESIMPULAN}

Dokumentasi

keperawatan

merupakan bentuk dokumen asuhan keperawatan sebagai salah satu alat pembuktian atas tindakan perawat selama menjalankan tugas pelayanan keperawatan. Dokumen asuhan keperawatan sangat diperlukan untuk kepentingan pasien maupun perawat, akan tetapi pada kenyataannya masih banyak dokumen asuhan keperawatan yang isinya belum sesuai baik dari segi kuantitas maupun kualitas.

\section{SARAN}

Untuk meningkatkan kualitas pelayanan dalam hal kelengkapan pendokumentasian asuhan keperawatan adalah meningkatkan frekuensi pengawasan dan penilaian terhadap pelaksanaan pendokumentasian asuhan keperawatan di rumah sakit. Peningkatan pelatihan terhadap pendokumentasian asuhan keperawatan yang dapat dilakukan secara berkala. 


\section{REFERENSI}

Asmadi. (2008). Konsep Dasar

Keperawatan. Jakarta: EGC

Budiarto, E. (2002). Biostatistik untuk

Kedokteran dan Kesehatan

Masyarakat.Jakarta: EGC.

Biki, P.A.U, (2015). Gambaran Kinerja

Perawat dalam Memberikan

Asuhan Keperawatan di Ruang

Interna di RSUD PROF.

DR.H.Aloei Saboe Kota

Gorontalo. Universitas Negeri

Gorontalo: Jurnal Keperawatan..

Depkes. (2005). Keputusan Menteri

Kesehatan RI Nomor

836/MENKES/SK/2005, tentang

Pedoman Pengembangan

Manajemen Kinerja Perawat dan

Bidan. Jakarta. .

Hidayat, A. A. A. (2011). Pengantar

Konsep Dasar Keperawatan. Ed.

2. Jakarta: Salemba Medika

Hariyati, T.S. (1999). Hubungan antara pengetahuan aspek hukum dari perawat dan karakteristik perawat dengan kualitas pendokumentasian asuhan keperawatan di Rumah Sakit Bhakti Yudha 1999 (Tesis, tidak dipublikasikan). Program Pasca
Sarjana Program Studi Kajian

Administrasi Rumah Sakit

Fakultas Kesehatan Masyarakat

Universitas Indonesia, Jakarta.

Ilyas, Yaslis. (2002), Kinerja: Teori, Penilaian, dan Penelitian, Pusat

Kajian Ekonomi Kesehatan

Fakultas Masyarakat Universitas Indonesia, Depok

Kemenkes RI. (2015). Profil Kesehatan Indonesia Tahun 2014. Jakarta..

Kozier, Barbara. (2010). Buku Ajar Fundamental Keperawatan; Konsep, Proses dan Praktik edisi 7 Volume. Jakarta: EGC.

L.M. Harmain, Siswanto. 2013. FaktorFaktor Yang Berhubungan Dengan Kelengkapan

Pendokumentasian Asuhan

Keperawatan: Jurnal

Keperawatan Indonesia, Volume 16 No.2, Juli, hal 77-84 pISSN 1410-4490, eISSN 2354-9203.

Rosdahl, B. C. \& Kowalski, T. M. (2014). Buku Ajar Keperawatan Dasar. Ed.10.Vol 1. Jakarta: EGC

Supratman, Yuni Wulan Utami.2 009. Pendokumentasian Asuhan Keperawatan Ditinjau Dari Beban Kerja Perawat: Berita Ilmu 
Keperawatan ISSN 1979-

2697,Vol. 2 No. 1, Maret 2009: 7 -

12.

Simamora, R. H. (2019). Menjadi Perawat yang: CIH'HUY. Surakarta: Kekata Publisher.

Simamora, Roymond H. 2010.

Komunikasi dalam Keperawatan, Ed 1 hal 210. Jember: Univesity Press.

Simamora, Roymond H. Dokumentasi Proses Keperawatan, `Ed 1 hal 144. Jember: University Press.

Simamora, Roymond H. 2008. Peran Manajer dalam Pembinaan Etika Perawat Pelakasanaan dalam Peningkatan Kualitas Pelayanan Asuhan Keperawatan: Jurnal IKESMA, Ed 4, 2.

Potter, P. A \&Perry, A. G. 2005. Buku Ajar Fundamental Keperawatan.Jakarta: EGC.

Potter, P.A.,\& Perry, G.A. 2010. Fundamental of nursing (Volume 2, 7th Ed.). ST. Louis: Mosby Year Book.

Potter, P. A., \& Perry, A. G., (2013). Fundamentals of nursing. ( $\left.8^{\text {th }} \mathrm{ed}\right)$. Elsevier. 